This is an author produced version of a paper published in Scandinavian Journal of Forest Research.

This paper has been peer-reviewed but may not include the final publisher proof-corrections or pagination.

Citation for the published paper:

Daniel Hodge, Vilis Brukas \& Alexandru Giurca. (2017) Forests in a bioeconomy: bridge, boundary or divide?. Scandinavian Journal of Forest Research. Volume: 32, Number: 7, pp 582-587. http://dx.doi.org/10.1080/02827581.2017.1315833.

Access to the published version may require journal subscription. Published with permission from: Taylor \& Francis Group.

Epsilon Open Archive http://epsilon.slu.se 
1 Forests in a bioeconomy: bridge, boundary or divide?

2 Daniel Hodge $^{1^{*}}$, Vilis Brukas ${ }^{1}$, Alexandru Giurca ${ }^{2}$

31 Department of Southern Research Centre, SLU, Alnarp SE-230 53, Sweden

42 Chair of Forest and Environmental Policy, University of Freiburg, Tennenbacher Str.

5 4, Freiburg D- 79106, Germany

$6 \quad *$ Corresponding author: daniel.a.hodge@icloud.com 


\section{Forests in a bioeconomy: bridge, boundary or divide?}

Bioeconomy is an emerging concept that is gaining momentum both in science and policy. Within the forest sector, the bioeconomy discourse is already shaping the international forest policy debate. Given the sector's importance for the national economy, this study investigates the perceptions of bioeconomy by forest owners, forest industry and ENGOs in Sweden. Drawing on cognitive and ideological dimensions of political bargaining, we analyse to which extent the bioeconomy serves as a bridging concept, a dividing concept or a boundary object.

The results show that the bioeconomy is a broadly accepted concept, perceived as a natural extension of the Swedish forestry model. Results indicate that bioeconomy is well aligned with the key characteristics of a boundary object, i.e. serving specific interests of different forest stakeholders under the generally accepted conceptual umbrella. We did not identify dividing effects of any substance. On the contrary, the interviews provide a strong indication that bioeconomy serves the Swedish forest sector as a bridging concept that brings closer rather than antagonises the different actors.

Keywords: Bioeconomy, forest sector, Sweden, bridging concept, boundary object, frame analysis

\section{Introduction}

Defined as an "economy based on biomass for food, feed, energy and other purposes, rather than fossil-based resources", bioeconomy is an emerging concept both in science and policy (Staffas et al. 2013). Although its meaning is still in flux, increasing popularity of bioeconomy suggests that it has the potential to become a "new influential global metadiscourse" and consequently influence forests and forestry (Pülzl et al. 2014).

Forests are expected to provide a significant contribution to a bioeconomy (Scarlat et al. 2015; Ollikainen 2014), not least in a country like Sweden that is rich on forest and is the world's second largest exporter of pulp, paper and wood products (Swedish Forest Industries Federation 2012). Sweden is thus well positioned for the transition to a 
bioeconomy (Formas 2012), and is expected to undergo significant structural changes

36 (Hetemäki 2014; Socaciu 2014).

37 There is a growing body of research exploring the concept of bioeconomy (Goven and Pavone 2015; Schmidt et al. 2012; Staffas et al. 2013), including its role in reframing forest discourses and shaping forest policy (Kleinschmit et al. 2014; Pülzl et al. 2014).

40 However, the existing literature still lacks empirical insights into the role of bioeconomy 41 in forest policy-making.

This paper draws on the importance of cognitive and ideological dimensions (Roe 1991; Shore and Wright 1997) in the formation of policy discourses. Discourses, resulting ideas and arguments are considered to have performative power, i.e. they shape actors' views, influence their behaviour, beliefs and interests, and ultimately lead to institutional change (Arts et al. 2010; Pülzl et al. 2014). Bioeconomy is seen here in the context of the motivations of the actors choosing certain conceptual interpretations that then reside in the interfaces between organizations or groups of people (Huvila 2011). Here, we hypothesise that the Swedish forest stakeholders may choose between three possible ways through which bioeconomy could be used as a discursive vehicle:

(1) Boundary object. Star and Griesemer (1989) introduced the notion of "boundary objects" as an entity shared by several different communities but used differently by each of them. A number of studies (e.g. Giorgi and Redclift 2000; Huvila 2011; Oppermann 2011) applied the concept in the analysis of bounding discourses. As a boundary object, the bioeconomy would be widely embraced by different actors as a progressive concept, at the same time being assigned very different meanings in accordance to actors' own values and interests. Boundary objects normally have a purposeful nature and, as such, they cannot be viewed as politically neutral or 
necessarily consensual (Huvila 2011).

60

61

62

63

64

65

66

67

68

69

70

(2) Bridging concept. Alternatively, bioeconomy could serve as a progressive concept bridging the different interests between actors. Defined by Baggio et al. (2015), a bridging concept differs from a boundary object in that it "actively links fields and stimulates dialog". The notion of bridging concepts has been discussed in different contexts as well, e.g. Davoudi et al. (2012) discuss resilience as a bridging concept that is translated from the natural to the social world and then applied to planning. In the case of the forest sector, bioeconomy could bridge the difference between actors whose interests have traditionally conflicted.

(3) Dividing concept. A third way in which bioeconomy could eventuate is as a dividing concept. Different understandings of the same concepts, facts, problems and opportunities often create political struggles (Fischer 2003). Subsequently, divergent frames may give rise to intensified competition (Schön and Rein 2004). As indicated by other studies on forest actors' perceptions (Lindahl 2015), the bioeconomy concept may be as well divisive, as it could be embraced by production-oriented actors but rejected by environmental actors as a justification for intensified forestry practices.

Therefore, this study aims to: (i) examine how bioeconomy is perceived by three main groups of Swedish forest stakeholders; and (ii) investigate whether bioeconomy is evolving as bridging concept, a dividing concept or a boundary object within the forest discourse in Sweden. 


\section{$81 \quad$ [Insert Figure 1 near here]}

82

\section{Materials and Methods}

\section{Data collection}

85 Initially, purposive sampling was used to identify the most pertinent actors in the Swedish 86 forest sector. Accordingly, the organisations approached and the individuals interviewed

87 in this study were chosen according to a preconceived, but reasonable initial set of criteria 88 (Sandelowski et al. 1992). We targeted larger organisations within the sector with the assumption that, as larger lobby groups and forest producers, they are both more aware

90 of international trends influencing forest policy and have a greater influence on the

91 development of national forest policy. For example, the Federation of Swedish Farmers

92 (LRF) and Swedish Forest Industries Federation were included as organisations representing large cohorts of forest owners and industries, and consequently exerting weighty influence on the Swedish forest policy arena. For similar reasons, we targeted representatives of the respective organisations, and/or engaged in communication or 96 lobbying for their cause.

In total, we sampled 12 experts, divided equally between three groups of organisations, forest industry, forest owner associations and environmental nongovernmental organisations (ENGO) (Table 1). Although some organisations could have

100 been classified as either a forest owner or forest industry (e.g. Södra), classification was

101 based on how the organisations identified themselves. The chosen format of semi-

102 structured interviews enabled to retrieve relevant and comparable information at the same 103 time allowing unconstrained conversation offering further insights into issues of interest 104 (Turner 2010). Each interview opened with some personal background and also project 
105 background questions, with the intent of making the interviewee more at ease and more

106 likely to speak openly. All interviewees were asked the same set of open-ended questions

107 which focused on the interviewees' interpretation of the bioeconomy (i.e., defining the

108 concept), and on their perception of bioeconomy as a bridge, divide or boundary concept;

109 here the open questions focused on actors' beliefs as well as perceived risks and

110 opportunities associated with bioeconomy. The final questions focused on the expected

111 impacts of bioeconomy on forests and forest management. All interviews were conducted

112 between 28 October 2015 and the 5 January 2016 by the first author of this study.

113 Interviews were taken in person at the premises of interviewees' organisations or per

114 telephone. Each interview lasted between 20 and 45 minutes and was recorded and later

115 transcribed verbatim.

116 [Insert Table 1 near here]

117 Data analysis

118 Two approaches were used to analyse the produced interview data: content analysis and

119 frame analysis. Firstly, key themes were identified and then categorised as being new

120 opportunities for the forest sector provided by a bioeconomy or forces that were either

121 drivers or obstacles for the progression of a bioeconomy (Spencer et al. 2003). Secondly,

122 frame analysis was used to better understand the perceptions of bioeconomy. Frame

123 analysis delves deeper than identifying common themes as it encompasses the entire tone,

124 context and impression portrayed by the interview, as well as the transcribed text, to

125 provide a description. Typically it provides a way to investigate an actor's organisation

126 of experience and the action biases they promote (Entman 1993). Identifying frames from

127 the transcribed interviews allows an understanding of how the concept of a bioeconomy

128 is perceived and used by the various actors interviewed. 
130 frames. The themes, summarised in Table 2, were elicited as responses defining

131 bioeconomy and the drivers, obstacles and opportunities related to a bioeconomy. Frames

132 were identified from the transcribed interviews based on both the responses to a specific

133 set of questions that aimed to elucidate how bioeconomy was perceived and the overall

134 impression given by the interview. The results of the frame analysis, summarised in

135 Figure 2, were then used to answer the question of whether the bioeconomy concept was

136 being used as a boundary object, or a bridging, or a dividing concept.

\section{Results}

\section{Understanding bioeconomy: perceived opportunities, drivers and obstacles}

139 What is a bioeconomy?

140 In general, all three actor groups perceived bioeconomy positively. Described by the

141 industry group as "a vision...for Sweden and for the world", bioeconomy was also

142 identified by the ENGO group as "something that is a very vital and necessary part of a

143 sustainable society" and the owners as "a positive thing [...] will help us move forward".

144 Similarly, all three groups agreed that bioeconomy was defined as "the part of [an]

145 economy built on the sustainable production of renewable materials from nature".

146 Owners also recognised that bioeconomy represents "a shift from the industrial fossil

147 based economy" as did ENGOs stating that "[it] implies [...] a transition of the economy

148 from the present one".

149 Bioeconomy was also viewed as a response to the global issues of resource

150 depletion and increasing carbon emissions. As a consequence, bioeconomy promoted

151 forests as a global resource, as identified by an ENGO, "if we really are going to build 
152 this renewable society where forest biomass plays a big role [...] there are potentials to increase biomass production globally as we have deforested areas, degraded forests".

154 What opportunities does a bioeconomy present?

155 Bioeconomy was perceived as an opportunity to communicate, both to inform society but 156 also to promote the forest sector. ENGOs recognised that as a term, bioeconomy could be 157 used to inform people "who don't have a lot of knowledge about environmental issues or 158 sustainability issues" and that it can be used to get people "interested in something they 159 weren't before". The industry and owner groups also saw the term as an opportunity to 160 both "to tell our story and show how good our products are" and that it "makes the whole sector more accepted" by showing the forest sector as part of a greener future.

162 What are the drivers for a bioeconomy?

163 Climate change was a major driver identified by all groups. Bioeconomy was identified as "an important part of the solution" for climate change, with all groups recognising that "we must substitute fossil fuel based raw materials and energy" in response to increasing

166 carbon emissions. Also based on the premise of substituting non-renewable products, the 167 need for sustainability was also perceived as a significant driver for a bioeconomy. 168 Identified by all three groups, sustainability was seen as a necessary response to 169 increasing population demand and limited resources and consequently, bioeconomy was seen as "a very vital and necessary part of a sustainable society".

All three groups of informants perceived the economic development as a primary 172 motivation for developing bioeconomy. The industry group in particular recognised 173 bioeconomy as "a way to find new markets and new products and new ways of using this raw material" and emphasised its importance by stating that "being able to make this transition to a new economy, a bioeconomy, [is] vital for survival". 

that although "people want to be eco-friendly" there was a perceived need for regulation

178 because "we don't have time for everything to be so eco-friendly as possible in the world, have to move it on a bit", which indicated that regulation was needed to drive behavioural

180 change. For this reason, "regulations [...] that are in favour of sustainably produced 181 products" could promote a transition to a bioeconomy "by stopping the bad things". The industry group likewise recognised that national and international policy were a necessary driver to "to promote new ideas and transform society".

What are the obstacles for a bioeconomy?

185 Societal disconnect from nature was cited as one of the major obstacles that could prevent progress of a bioeconomy. Both the ENGO group and the owner group mentioned society's alienation from nature, which they attributed to urbanisation. This meant that "fewer and fewer people have actual knowledge and experience [...] about what nature

189 is and how it should be managed". This was seen as an obstacle because, as stated by an

190 ENGO representative, "understanding of the forests and their environmental values and ecosystem services is deteriorating [...] and that would then potentially undermine the forest push that we manage them sustainably".

As well as a driver, regulation was also seen as potential obstacle for the

194 development of a bioeconomy. Bureaucracy in general was identified as an issue because

195 it could make forest utilisation so complex and difficult that "forest owners will not harvest". Regulation was also identified by the industry group as an obstacle when policies failed to distinguish bio-based energy from fossil based energy and as a result meant it was "cheaper to import fossil fuels than to use renewable ones". identified as an obstacle for a transition to a bioeconomy. Normative resistance was seen 
as an impediment for alternative uses of biomass because it was not "what we are used to

doing". Competition was also perceived as an issue by an owner stating that, "there are institutions and sectors that are against the use of forest" that have "very strong economic interests, which use lobbies and politics to promote their own products".

When viewing the forest as a limited resource for a developing bioeconomy, there was a gradient of decreasing concern from the ENGO group to the owner and industry groups. The ENGO group promoted the view that forest use is already at a limit, saying, "forest [in Sweden] is already being over exploited" and emphasising a change in biomass consumption patterns. The owner group also recognised that in Sweden "we are cutting as much as we can" but identified that there was potential to increase growth, for example with "better seed orchards" and "denser stands". The industry group viewed forests as a global resource that can be increased, stating, "we can still do a lot more to have more productive forests".

214 [Insert Table 2 near here]

\section{Bioeconomy as a bridge, boundary or divide}

216 In general, there was a common understanding of bioeconomy between the groups, which

217 indicated that bioeconomy had potential as a bridging concept. Delving deeper, the 218 interviews exhibited a range of understandings and as a result, there was no clear 219 distinction between the groups in terms of how the concept was used. Instead perceptions 220 of the bioeconomy were more a function of individual understandings rather than beliefs 221 held in common for an actor group (Figure 2).

The notion that bioeconomy could be regarded as a bridging concept was supported by interviews from all three actor groups. The industry group recognised that

224 "we have to make it a concept that we can work on together as a whole society [...] we need a common base in the vision". Similarly the ENGO group identified that "if we use 
[bioeconomy] just to reach our own political goals [...] it's not going to be very

227 constructive". Deeper than commonalities, any indication that the bioeconomy concept included a shift in attitude was a sign that the concept provided a bridge between traditionally disparate groups. For example, an ENGO actor recognised that "it's good, better, to use more fibres to replace other things" and industry and owners acknowledged that "it's important for us to redefine ourselves and become a part of the future" and need to "shift from a traditional industrialised economy".

Bioeconomy as a boundary object had less support from interviews than it did as

234 a bridging concept. Owners in particular supported the notion, with three of the four owners interviewed regarding bioeconomy synonymously with forestry stating that, "we are the bioeconomy" and "our mission has not changed but the wording has changed". This view indicates that, counter to attitudes that supported bioeconomy as bridging object, bioeconomy is a tool for society to accept forestry as it is.

Of the three alternatives, bioeconomy a dividing concept had the least support, with only the ENGO group providing a nominal backing. The main reason this interview was categorised as dividing is that bioeconomy was perceived as "rhetoric" used by the "the forest industry and others [...] to increase production, increase fertilisation, and more exotic species".

$244 \quad$ [Insert Figure 2 near here]

\section{Discussion}

246 In general, bioeconomy was perceived positively by all interviewees. In this sense, it acts

247 as a "nirvana concept" that embodies an ideal image of the world, which societies strive 248 to reach (Molle 2008). The fact that each informant could define bioeconomy indicates 249 that the concept has already pervaded the national forest discourse in Sweden. Although 250 all interviewees perceived the concept positively only a few exhibited an understanding 
deeper than a vague sense implying a push towards a more sustainable society. The broad understanding could imply that the concept is still in its infancy and needs further refinement before it can influence forest policy. Alternatively, the openness of the definition can be viewed as a strength and consequently a reason why the concept had universal acceptance between the diverse groups interviewed and was supported as a bridging concept. This is in line with Kleinschmit et al. (2014) who found that bioeconomy could diminish the traditionally strong actor-coalitions of the forest sector. provided scope for stakeholders to interpret bioeconomy in their own ways, treating it as a boundary object. Predominantly it was the forest owners, who interpreted bioeconomy as a validation of forestry and as a consequence, perceived themselves as synonymous with bioeconomy. In some regards this view may be accurate as forest owners supply raw forest material. This, however, implies a normative resistance to any change from a traditional forest management model. In fact, this difference in attitude clearly distinguished the forest owners from the other two groups. As it is often the case with boundary objects, they are usually employed by a particular group to differentiate themselves from others (Huvila 2011). An attitude that equates bioeconomy with forests and forestry - not altogether surprising in a country where the forest sector is so dominant - could present a barrier for widespread adoption of the concept in Sweden. study is that actors framed the concept in a way that aligns well with the current Swedish

272 forest model. Although there was a recognition that forests were a limited resource, 273 primarily by the ENGOs, there was simultaneously little sense that there was any need 274 for change in production or consumption behaviour. Rather, there was an expectation that 275 improved efficiencies and other developments will help meet future production demands. 
Lindahl et al. (2015: 11) describes this attitude as the "more of everything pathway", an "optimistic view that it is possible to create more of existing resources" and as such, can be seen as an extension of the Swedish forest model that traditionally has prioritised wood production.

This study aimed by no means to be exhaustive nor claimed to be representative

281 for the entire bioeconomy discussion in Sweden. The particular focus on forests in the

282 bioeconomy allowed for some first insights into how the "moving" bioeconomy concept

283 is perceived by some purposefully chosen forest actors, and for discussing the

284 implications of these findings. It was beyond the scope of this study to dwell deeper into actors' interests and strategies. However, the infancy of the concept and actors' interests may have sponsored narrower frames in which problem formulations were delimited and

287 thus revealed perceptions that provided a rather optimistic view (Lindahl 2015). As the political bioeconomy discourse becomes more established and materializes into Swedish forest policy, future studies could follow up on this investigation and extend the study to a larger population of actors, perhaps from other bioeconomy-relevant sectors (e.g., agriculture, energy sector, chemical industry etc.).

At this time however, the revealed actors' perceptions offer the potential to shape 293 policy discourse towards the notion of bioeconomy as a natural extension of the traditional Swedish forestry model. Whether motivated by a need for society to be sustainable or a need for the industry to survive, all of the interviewees see bioeconomy as a desirable future. Industry and ENGOs see it as a vehicle for progress, while for forest owners it rather constitutes an approval of the current practices. Thus, the owners perceive bioeconomy more as a pathway for society to progress towards them. In other

299 words, owners would expect the society to give a "green card" for the current forestry 300 practices, due to a better understanding of the role of forests in bioeconomy. In either 
interpretation, such consensual "nirvana" (nobody is against bioeconomy) can risk being

302 hijacked by groups seeking to legitimize their own agendas (Molle 2008). This caveat aside, bioeconomy has a clear potential to serve a bridging role, bringing together forest actors with different interests. Let us conclude with the words of one of the interviewees: "[bioeconomy] is a buzzword, but a useful buzzword”.

\section{Acknowledgements}

We would like to gratefully acknowledge the contribution of those interviewed whose time and interest made this study possible.

\section{References}

Arts B, Appelstrand M, Kleinschmit D, Pülzl H, Visseren-Hamakers I, Eba'a Atyi R,

Baggio JA, Brown K, Hellebrandt D (2015). Boundary object or bridging concept? A network of resilience. Ecol. Soc.20: 2, http://dx.doi.org/10.5751/ES-07484-200202.

Davoudi S, Shaw K, Haider LJ, Quinlan AE, Peterson GD, Wilkinson C, Fünfgeld H, McEvoy D, Porter L (2012). Resilience: a bridging concept or a dead end? Plan. Theory Pract. 13(2): 299-333.

Entman RM (1993). Framing: toward clarification of a fractured paradigm. J. Commun. 43: 51-58.

Fischer, F (2003). Reframing public policy: discursive politics and deliberative practices. Oxford University Press, Oxford.

Formas (2012). Swedish research and innovation strategy for a bio-based economy. Stockholm: Swedish Research Council for Environment, Agricultural Sciences and Spatial Planning (FORMAS).

Giorgi L and Redclift M (2000). European environmental research in the social sciences: research into ecological modernization as a "boundary object." Eur. Environ. 10(1): $12-23$. 
331 Goven J and Pavone V (2015). The bioeconomy as political project a polanyian analysis. Sci. Techno. Hum. Val. 40: 302-337.

Hetemäki L (2014). Introduction. In: Hetemäki L (Ed.) Future of the European forestbased sector: structural changes towards bioeconomy. European Forest Institute.

Huvila I (2011). The politics of boundary objects: hegemonic interventions and the making of a document. J. Am. Soc. Inf. Sci. Technol. 62(12): 2528-2539.

Kleinschmit D, Ingemarson F and Holmgren S (2012). Research on forest policy in Sweden - Review. Scand. J. For. Res. 27: 120-129.

Kleinschmit D, Lindstad B H, Thorsen B J, Toppinen A, Roos A, Baardsen S (2014). Shades of green: a social scientific view on bioeconomy in the forest sector. Scand. J. For. Res. 29: 402-410.

Lindahl KB (2015). Actors perceptions and strategies: forests and pathways to sustainability. In: Lindahl KB, Westholm E, Kraxner F (Eds.) The future use of nordic forests. Springer International Publishing.

Lindahl KB, Sténs A, Sandström C, Johansson J, Lidskog R, Ranius T, Roberge J (2015). The Swedish forestry model: more of everything? For. Policy Econ. http:// dx.doi.org/10.1016/j.forpol.2015.10.012.

Molle F (2008). Nirvana concepts, narratives and policy models: Insight from the water sector. Water Altern. 1: 131-156.

Nisbet MC and Mooney C (2009). Framing science. Sci. 316.

Ollikainen M (2014). Forestry in bioeconomy - smart green growth for the humankind. Scand. J. For. Res. 29: 360-366.

Oppermann E (2011). The discourse of adaptation to climate change and the UK climate impacts programme: describing the problematization of adaptation. Clim. Dev. 3: 71-85.

Pülzl H, Kleinschmit D, Arts B (2014). Bioeconomy - an emerging meta-discourse affecting forest discourses? Scand. J. For. Res. 29: 386-393.

Roe E (1991). Development narratives, or making the best of blueprint development. World Dev. 19: 287-300.

360 Sandelowski M, Holditch-Davis D, Harris BG (1992). Using qualitative and quantitative methods: the transition to parenthood of infertile couples. In: Gilgun JF, Daly K, Handel G (Eds.) Qualitative Methods in Family Research. Sage, pp. 301-322.

Scarlat N, Dallemand JF, Monforti-Ferrario F, Nita V (2015). The role of biomass and bioenergy in a future bioeconomy: policies and facts. Environ. Dev. 15:3-34. 
Schmidt O, Padel S, Levidow L (2012). The bioeconomy concept and knowledge base in a public goods and farmer perspective. Bio-based Appl. Econ. 1: 47-63.

Schön D and Rein M (1994). Frame reflection: toward the resolution of intractable policy controversies. Basic Books, New York.

Shore C and Wright S (1997). Policy: A new field of anthropology. In: Shore C and Wright S (Eds.), Anthropology of policy: critical perspectives on governance and power. Routledge, London.

Spencer L, Ritchie J, O’Connor W (2003). Analysis: practices, principles and processes. In: Ritchie J and Lewis J (Eds.) Qualitative research practice: a guide for social science students and researchers. Sage.

Socaciu C (2014). Bioeconomy and green economy: European strategies, action plans and impact on life quality. Bulletin of University of Agricultural Sciences and Veterinary Medicine Cluj-Napoca. Food Sci. Technol. 7: 11-10.

Staffas L, Gustavsson M, McCormick K (2013). Strategies and policies for the bioeconomy and bio-based economy: an analysis of official national approaches. Sustainability 5: 2751-2769.

Star SL and Griesemer JR (1989). Institutional ecology, translations' and boundary objects: amateurs and professionals in Berkeley's Museum of Vertebrate Zoology, 1907-39. Soc. Stud. Sci. 19: 387-420.

Swedish Forest Industries Federation (2012). The forest industry - the driver for a sustainable bioeconomy. Swedish Forest Industries Federation, Stockholm.

Turner DW (2010). Qualitative interview design: a practical guide for novice investigators. Qual. Rep. 15: 754-760. 
Table 1. Interviewed organisations.

\begin{tabular}{lll}
\hline Group & Organisation & $\begin{array}{l}\text { Number of } \\
\text { interviews }\end{array}$ \\
\hline ENGO & Forest Stewardship Council & 1 \\
\hline ENGO & Greenpeace & 1 \\
\hline ENGO & Swedish Society for Nature & 1 \\
\hline Industry & Fonservation & 1 \\
\hline Industry & World Wildlife Fund & 1 \\
\hline Industry & Svenska Cellulosa Aktiebolaget & 2 \\
\hline Owner & Federation of Swedish Farmers & 2 \\
\hline Owner & Södra & 2 \\
\hline
\end{tabular}

389 
390 Table 2. Summary of opportunities, obstacles and drivers identified by interviewed

391 groups. An ' $\mathrm{X}$ ' denotes that there was evidence from every interview within a group that

392 supported the identified themes.

\begin{tabular}{l|ccc}
\hline \multicolumn{1}{l|}{ ENGOS } & INDUSTRY & OWNERS \\
\hline COMMUNICATION TOOL & & $\mathrm{X}$ & $\mathrm{X}$ \\
\hline DRIVERS & & & \\
CLIMATE CHANGE & $\mathrm{X}^{*}$ & $\mathrm{X}$ & $\mathrm{X}$ \\
ECONOMIC DEVELOPMENT & $\mathrm{X}$ & $\mathrm{X}$ & $\mathrm{X}$ \\
REGULATION & $\mathrm{X}$ & $\mathrm{X}$ & $\mathrm{X}$ \\
SUSTAINABILITY & $\mathrm{X}$ & $\mathrm{X}$ & \\
\hline OBSTACLES & & & $\mathrm{X}$ \\
REGULATION & & $\mathrm{X}$ & $\mathrm{X}$ \\
RESISTANCE & & $\mathrm{X}$ & $\mathrm{X}$ \\
RESOURCE LIMITATION & $\mathrm{X}$ & & $\mathrm{X}$ \\
SOCIETAL DISCONNECT & $\mathrm{X}$ & & \\
\hline
\end{tabular}

393 Note: *There was no unanimous agreement within the group for this topic. 
395 Figure captions:

396 1. Figure 1. Three potential interactions between two groups that the bioeconomy concept can facilitate.

2. Figure 2. Summary of bioeconomy perceived as a boundary, bridging or dividing object for each of the three groups interviewed. 